\title{
Determinants of ADP-induced platelet aggregation in diabetes mellitus
}

\author{
D. B. Jones, T. M.E. Davis, E. Bown, R. D. Carter, J.I. Mann ${ }^{1}$ and R. J.Prescott ${ }^{2}$ \\ Diabetes Research Laboratories, Radcliffe Infirmary, Oxford; ' Department of Community Medicine and General Practice, University of \\ Oxford, and ${ }^{2}$ Medical Computing and Statistics Unit, University of Edinburgh, UK
}

\begin{abstract}
Summary. ADP-induced platelet aggregation was measured in 15 Type 1 (insulin-dependent) diabetic patients, 15 Type 2 (non-insulin-dependent) diabetic patients and in 15 non-diabetic control subjects. Simultaneous measurements were made of fasting blood glucose, glycosylated haemoglobin, serum insulin, total plasma cholesterol, cholesterol in the lipoprotein subfractions, total triglycerides and platelet phospholipid fatty acid levels. Regression analysis of aggregation against the biochemical variables within the three groups revealed that there was no significant difference in the associations with aggregation between the groups. When the data was
\end{abstract}

pooled, blood glucose $(p<0.01)$ and glycosylated haemoglobin $(p<0.05)$ demonstrated significant associations with aggregation. Multiple regression analysis was then applied; only blood glucose $(p<0.05)$ had an independent effect on aggregation. Platelet aggregation in diabetic patients and nondiabetic patients appears to be related directly only to blood glucose levels.

Key words: Platelet aggregation, diabetes mellitus, glucose, insulin, cholesterol, fatty acids.
The factors which determine the degree of platelet aggregation in diabetes mellitus are disputed. Although blood glucose and insulin are considered to be important by some authorities [1-3], others have suggested that there is no direct association between aggregation and glycaemia [4]. However, improvement in diabetic control was associated with reduced platelet aggregation in two other studies [5, 6]. Animal work using streptozotocin-induced diabetic rats also suggests a role for glycaemia in altered platelet aggregation [7].

The discovery of the role of thromboxane in aggregation [8] led to the possibility that it was involved in the increased platelet activity seen in diabetes. Subsequent work demonstrated that thromboxane synthesis by platelets may be increased [9], and that circulating levels of the thromboxane metabolite $\left(\mathrm{TXB}_{2}\right)$ are elevated in diabetes [10]. In addition, the platelet levels of the thromboxane precursor arachidonic acid are low in diabetes and the levels correlate inversely with the percentage of glycosylated haemoglobin [11]. Arachidonic acid

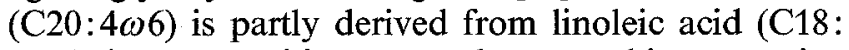
$2 \omega 6$ ), but competition occurs between this conversion and that of linolenic acid (C18:3 $\omega 3)$ and eicosapentaenoic acid (C20:5 $\omega 3$ ) [12], which utilises the same enzyme system. Eicosapentaenoic acid is subsequently metabolised to an analogue of thromboxane which has a much weaker aggregatory property [13]. It is therefore possible that the aggregatory influence of the vascular prostaglandins is proportional to the relative amounts of thromboxane and analogues of thromboxane derived from the platelet levels of these fatty acids.

We have used mutliple regression analysis to attempt to distinguish the primary influence on platelet aggregation from the secondary effects in diabetic patients and non-diabetic subjects.

\section{Subjects and methods}

\begin{abstract}
Adenosine diphosphate (ADP)-induced aggregation was measured simultaneously with fasting blood glucose, glycosylated haemoglobin, serum insulin, plasma lipids and platelet phospholipid fatty acid levels in Type 1 (insulin-dependent), Type 2 (non-insulin-dependent) diabetic patients and in non-diabetic control subjects to determine which factors predominate in controlling the degree of platelet activity and to examine specifically the role of the platelet $\omega 6$ and $\omega 3$ fatty acids.

Fifteen Type 1 diabetic patients, 15 Type 2 diabetic patients and 15 non-diabetic control subjects were studied. The diabetic patients were drawn from the Oxford diabetic clinics. The degree of glycaemic control varied; some of the patients were poorly controlled and were studied during a period of in-patient stabilisation. The control subjects were members of hospital and laboratory staff. All patients and control subjects were male non-smokers who were taking no regular medication. The Type 1 patients were being treated with insulin in a mean dose of $0.84 \mathrm{U}$ per kilogram body weight. The Type 2 patients were being treated with diet alone. Patient and control subjects had not taken aspirin or any antiinflammatory drugs for 2 weeks prior to
\end{abstract}


the study. The Type 1 patients had a mean age of 44.7 years, the Type 2 patients had a mean age of 49.7 years and the control subjects had a mean age of 48.1 years. The mean duration of diabetes was 24.6 years in the Type 1 patients and 4.7 years in the Type 2 patients. The presence of retinopathy was determined by fundoscopy through dilated pupils. In the Type 1 patients, six had no retinopathy, four had background retinopathy and five had proliferative retinopathy. In the Type 2 patients, none of the patients had evidence of retinopathy. After an overnight fast, blood was taken to measure ADP-induced platelet aggregation, bood glucose, glycosylated haemoglobin $\left(\mathrm{HbA}_{1 \mathrm{c}}\right)$, serum insulin (in the Type 2 patients and control subjects only) and platelet phospholipid fatty acid levels.

ADP-induced platelet aggregation was measured by a new modification of the Born method using an aggregometer (Payton, Scarborough, Ontario, Canada). Platelet rich plasma (PRP) was obtained from $30 \mathrm{ml}$ of blood taken into $3 \mathrm{ml}$ of $3.8 \%$ sodium tricitrate by differential centrifugation at $700 \mathrm{rpm}$ for $15 \mathrm{~min}$. The PRP was then corrected to 250000 platelets per $\mathrm{mm}^{3}$ by the addition of platelet poor plasma (PPP) obtained by centrifugation of the remaining blood at $2000 \mathrm{rpm}$ for $20 \mathrm{~min}$. Volumes of $0.01 \mathrm{mmol} / \mathrm{l} \mathrm{ADP}$ between $2 \mu \mathrm{l}$ and $10 \mu \mathrm{l}$ were then added to separate cuvettes containing $0.25 \mathrm{ml}$ of corrected platelet plasma to produce a series of aggregation curves. The deflection from the baseline to the maximum response for each aggregation curve was then measured in $\mathrm{mm}$. These values were then divided by the volume in microlitres of ADP added to obtain a value for the deflection (mm) produced by this standard volume of ADP (i.e. $1 \mu 1)$. As each microlitre of $0.01 \mathrm{mmol}$ ADP added is equivalent to a final concentration of $0.004 \mathrm{mmol} / 1$, the final aggregation value is expressed as the mean deflection $(\mathrm{mm})$ produced by $0.004 \mathrm{mmol} / 1 \mathrm{ADP}$ over a range of ADP concentrations between $0.008 \mathrm{mmol} / 1$ ADP and $0.04 \mathrm{mmol} / 1 \mathrm{ADP}$. The value obtained therefore relates to both the first and second phase aggregation in a manner which is dependent on the sensitivity of the platelet to ADP. The more sensitive the platelets, the lower the dose of ADP at which secondary aggregation occurs and therefore the higher the aggregation value. The method appears to be influenced by cyclooxygenase inhibitors and is considered to partly reflect prostaglandin mediated aggregation events [14]. This is not the case with some other methods of calculating the aggregation value (e.g. the $\mathrm{ED}_{50}$ method for calculating the dose of $\mathrm{ADP}$ required to produce $50 \%$ of maximal aggregation) and consequently suggests that other aspects of aggregation are assessed [15].

Platelet phospholipid fatty acid levels were measured from $30 \mathrm{ml}$ of citrated blood. Following centrifugation at $180 \mathrm{~g}$ for $10 \mathrm{~min}$, platelet rich plasma was washed twice in $0.9 \%$ saline and recentrifuged at $500 \mathrm{~g}$ to produce a platelet pellet. Thin layer chromatography and gas liquid chromatography was carried out as previously described [11]. The percentage of each fatty acid was then obtained from the chromatograph and is presented as a percentage of total fatty acids.

Glucose was measured by a glucose oxidase method on a Unicam $\mathrm{AC1}$ autoanalyser (Pye, London, $\mathrm{UK}$ ), $\mathrm{HbA}_{1 \mathrm{c}}$ by an isoelectric focussing technique (normal range 6-8\% for our laboratory) [16], insulin by immunodiffusion following charcoal separation [17], and cholesterol by a Technicon Autoanalyser (Technicon, Basingstoke, UK) using the Liebermann-Burchard reaction and cholesterol in the lipoprotein fractions after precipitation with heparin, manganese chloride and sodium dodecyl sulphate $[18,19]$. Serum triglyceride was measured after enzymatic hydrolysis [20].

\section{Statistical analysis}

The significance of differences between the groups was assessed first by a Kruskal-Wallis one-way analysis of variance by ranks. Only if this was statistically significant at the $5 \%$ levels were pairs of groups then compared using the Wilcoxon rank sum test. To assess the effect of the biochemical variable on aggregation, each variable was considered separately. The regressions of aggregation on that variable were compared over the three subgroups. As no significant differences between the groups were revealed, the data were then pooled and the significance of the overall relationship between aggregation and that variable was determined. Finally, multiple regression was applied considering only those variables which individually had shown a significant association at the $10 \%$ level.

\section{Results}

The mean and standard deviation of the aggregation values and the biochemical variables are shown in

Table 1. Biochemical variables and aggregation values in Type 1 (insulin-dependent) diabetic patients, Type 2 (non-insulin-dependent) diabetic patients and non-diabetic control subjects

\begin{tabular}{|c|c|c|c|c|c|c|c|c|c|}
\hline & $\begin{array}{l}\text { Aggregation } \\
(\mathrm{mm} / \mathrm{\mu l} \text { ADP) }\end{array}$ & $\begin{array}{l}\text { Glucose } \\
(\mathrm{mmol} / \mathrm{l})\end{array}$ & $\begin{array}{l}\mathrm{HbA}_{1 \mathrm{c}} \\
(\%)\end{array}$ & $\begin{array}{l}\text { Insulin } \\
(\mathrm{mU} / \mathrm{l})\end{array}$ & $\begin{array}{l}\text { Total } \\
\text { cholesterol } \\
(\mathrm{mmol} / \mathrm{l})\end{array}$ & $\begin{array}{l}\mathrm{HDL} \\
(\mathrm{mmol} / \mathrm{l})\end{array}$ & $\begin{array}{l}\mathrm{LDL} \\
(\mathrm{mmol} / \mathrm{l})\end{array}$ & $\begin{array}{l}\text { VLDL } \\
(\mathrm{mmol} / \mathrm{l})\end{array}$ & $\begin{array}{l}\text { Triglyceride } \\
(\mathrm{mmol} / \mathrm{l})\end{array}$ \\
\hline Type 1 & $\begin{array}{r}6.8 \\
\pm 2.5\end{array}$ & $\begin{array}{r}11.1 \\
+\quad 5.5\end{array}$ & $\begin{array}{r}9.6 \\
+2.0\end{array}$ & & $\begin{array}{r}4.7 \\
\pm 0.9\end{array}$ & $\begin{array}{r}1.3 \\
\pm 0.2\end{array}$ & $\begin{array}{r}2.6 \\
\pm 0.5\end{array}$ & $\begin{array}{r}0.8 \\
\pm 0.6\end{array}$ & $\begin{array}{r}1.4 \\
\pm 0.5\end{array}$ \\
\hline Type 2 & $\begin{array}{r}7.2 \\
\pm 2.7\end{array}$ & $\begin{array}{r}10.4 \\
\pm \quad 2.4\end{array}$ & $\begin{array}{r}9.7 \\
\pm 1.7\end{array}$ & $\begin{array}{r}15.2 \\
\pm 10.0\end{array}$ & $\begin{array}{r}5.0 \\
\pm 0.8\end{array}$ & $\begin{array}{r}1.3 \\
\pm 0.2\end{array}$ & $\begin{array}{r}2.9 \\
\pm 0.8\end{array}$ & $\begin{array}{r}0.6 \\
\pm 0.4\end{array}$ & $\begin{array}{r}1.5 \\
+0.8\end{array}$ \\
\hline $\begin{array}{l}\text { Control } \\
\text { subjects }\end{array}$ & $\begin{array}{r}6.0 \\
\pm 1.8\end{array}$ & $\begin{array}{r}4.7 \\
\pm \quad 0.6\end{array}$ & $\begin{array}{r}7.1 \\
\pm 1.2\end{array}$ & $\begin{array}{r}21.6 \\
\pm 22.5\end{array}$ & $\begin{array}{r}5.0 \\
\pm 0.9\end{array}$ & $\begin{array}{r}1.4 \\
\pm 0.2\end{array}$ & $\begin{array}{r}2.9 \\
\pm 0.7\end{array}$ & $\begin{array}{r}0.8 \\
\pm 0.5\end{array}$ & $\begin{array}{r}1.6 \\
\pm 0.7\end{array}$ \\
\hline
\end{tabular}

$($ mean $\pm S D)$

Table 2. Platelet phospholipid fatty acid percentages in Type 1 (insulin-dependent) diabetic patients, Type 2 (non-insulin-dependent) diabetic patients and non-diabetic control subjects

\begin{tabular}{|c|c|c|c|c|c|c|c|c|c|c|c|}
\hline & $16: 0$ & $18: 0$ & $18: 1$ & $18: 2$ & $18: 3$ & $20: 3$ & $20: 4$ & $20: 5$ & $\begin{array}{r}\mathrm{C} 20: 0 \\
+\mathrm{C} 20: 1\end{array}$ & $\frac{20: 4}{20: 5}$ & $\frac{\omega 6}{\omega 3}$ \\
\hline Type 1 & $\begin{array}{r}19.1 \\
+\quad 5.0\end{array}$ & $\begin{array}{r}17.1 \\
\pm \quad 4.2\end{array}$ & $\begin{array}{r}16.2 \\
\pm \quad 3.1\end{array}$ & $\begin{array}{r}11.5 \\
\pm \quad 3.7\end{array}$ & $\begin{array}{r}0.5 \\
\pm 0.6\end{array}$ & $\begin{array}{r}2.0 \\
\pm 0.7\end{array}$ & $\begin{array}{r}16.4 \\
\pm \quad 5.6\end{array}$ & $\begin{array}{r}1.1 \\
\pm 0.3\end{array}$ & $\begin{array}{r}3.1 \\
+2.0\end{array}$ & $\begin{array}{r}16.2 \\
\pm \quad 8.0\end{array}$ & $\begin{array}{r}8.1 \\
+\quad 4.4\end{array}$ \\
\hline Type 2 & $\begin{array}{r}19.4 \\
\pm \quad 3.3\end{array}$ & $\begin{array}{r}16.8 \\
\pm \quad 2.9\end{array}$ & $\begin{array}{r}16.3 \\
\pm \quad 2.8\end{array}$ & $\begin{array}{r}7.7 \\
+\quad 2.1\end{array}$ & $\begin{array}{r}0.5 \\
\pm 0.6\end{array}$ & $\begin{array}{r}2.0 \\
\pm 0.5\end{array}$ & $\begin{array}{r}22.0 \\
\pm \quad 3.2\end{array}$ & $\begin{array}{r}2.5 \\
\pm 3.0\end{array}$ & $\begin{array}{r}3.5 \\
+1.3\end{array}$ & $\begin{array}{r}13.0 \\
\pm \quad 4.7\end{array}$ & $\begin{array}{r}5.5 \\
+\quad 1.6\end{array}$ \\
\hline $\begin{array}{l}\text { Control } \\
\text { subjects }\end{array}$ & $\begin{array}{r}19.1 \\
\pm \quad 4.3\end{array}$ & $\begin{array}{r}17.5 \\
\pm \quad 1.8\end{array}$ & $\begin{array}{r}16.1 \\
\pm \quad 2.4\end{array}$ & $\begin{array}{r}8.9 \\
\pm \quad 2.6\end{array}$ & $\begin{array}{r}0.7 \\
\pm 0.9\end{array}$ & $\begin{array}{r}1.8 \\
\pm 0.6\end{array}$ & $\begin{array}{r}22.0 \\
\pm \quad 4.2\end{array}$ & $\begin{array}{r}1.3 \\
\pm 0.4\end{array}$ & $\begin{array}{r}4.5 \\
\pm 1.8\end{array}$ & $\begin{array}{r}17.2 \\
\pm \quad 9.2\end{array}$ & $\begin{array}{r}17.5 \\
\pm \quad 9.1\end{array}$ \\
\hline
\end{tabular}


Table 1. There were no significant differences in aggregation between the three groups. Blood glucose and percentage glycosylated haemoglobin were significantly lower in the non-diabetic patients when compared with both diabetic groups $(p<0.001)$, but there was no difference between the diabetic groups. There was no significant difference between the non-diabetic group and the Type 2 patients in serum insulin levels. Total cholesterol, HDL cholesterol, LDL cholesterol, VLDL cholesterol and total triglycerides were not significantly different between the three groups.

The mean and standard deviation of the individual percentages of the platelet phospholipid fatty acids and their ratios are shown in Table 2 . C18:2 $\omega 6$ was significantly higher in the Type 1 diabetic group than in the Type 2 diabetic group $(p<0.01)$. C20:4 46 was lower in the Type 1 patients than in the non-diabetic patients $(p<0.01)$ and the Type 2 patients $(p<0.01)$. There was no significant difference between the non-diabetic patients and the Type 2 patients in percentage of C20:4 466 . The ratio of $\omega 6$ fatty acids $(\mathrm{C} 18: 2 \omega 6)$ and $\mathrm{C} 20: 4 \omega 6)$ to $\omega 3$ fatty acids (C18:3 $\omega 3$ and $\mathrm{C} 20: 5 \omega 3)$ was significantly higher in the non-diabetic patients than in the Type 1 patients $(p<0.001)$ and the Type 2 patients $(p<$ 0.0001 ). There was no significant difference in this ratio between the two diabetic groups.

When regression analysis was carried out, there were no significant differences between the three groups in the relationship between aggregation and any of the biochemical variables. When the results were pooled, significant associations were seen only with blood glucose $(p<0.01)$, glycosylated haemoglobin $(p<0.05)$, total cholesterol $(p<0.1)$ and LDL cholesterol $(p<0.1)$ at the $10 \%$ significance level. When multiple regression was applied considering only these four variables against aggregation, only blood glucose demonstrated a significant association $(p<0.05)$ (Fig. 1).

\section{Discussion}

Platelet aggregation in diabetic patients and non-diabetic patients appears to be primarily influenced by blood glucose level. It is therefore unlikely that platelets from diabetic patients are intrinsically different from those of non-diabetic patients; they merely reflect the hyperglycaemic environment. No statistically significant difference emerged in the degree of aggregation between the three groups in this study, although the previously well described trend of increased aggregation in diabetes was present. The explanation for this may lie in down-regulation of the response in the diabetic groups. It should be emphasised that multiple linear regression is a much more powerful statistical test than the Wilcoxon test.

Glucose-mediated changes in platelet behaviour may therefore contribute to the development of vascular damage (which is associated with poor diabetic con-

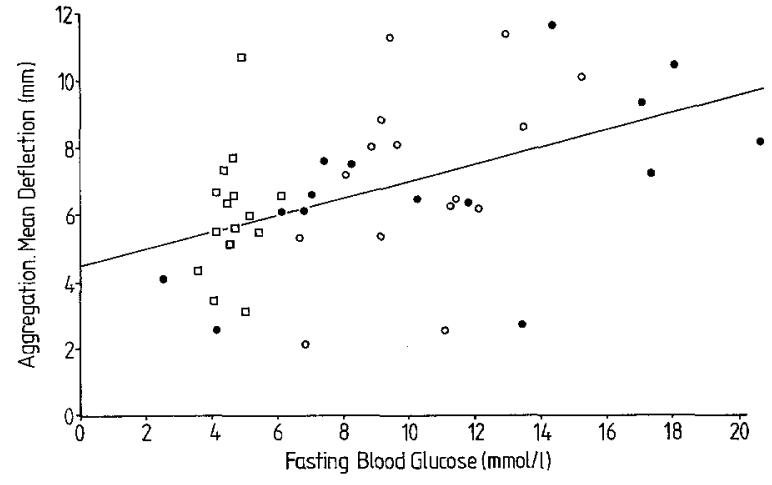

Fig. 1. ADP-induced platelet aggregation ( $\mathrm{mm}$ ) against fasting blood glucose (mmol/l) in Type 1 (insulin-dependent) diabetic patients $(\bullet)$, Type 1 (non-insulin-dependent) diabetic patients $(O)$ and in non-diabetic control subjects $(\square)(r=0.46)$

trol) $[21,22]$. This supports the view that the platelet abnormality seen in diabetes is secondary to the biochemical changes and not merely a response to vascular damage. These results strengthen the argument that platelets may have a central role in the development of microangiopathy.

The mechanism of the association between glycaemia and platelet aggregation is already well established in platelets from non-diabetic patients. Under conditions of normoglycaemia, glucose is absorbed from plasma and is metabolised to lactate via the Embden-Meyerhof pathway to produce $50 \%$ of the platelet energy requirements [23, 24]. It is feasible that under conditions of moderate hyperglycaemia a substrate (i.e. glucose)stimulated increase in adenine nucleotides synthesis might result in increased aggregability of the platelets with a secondary increase in platelet thromboxane production.

We have recently described an association between the level of arachidonic acid in platelet phospholipid and glycosylated haemoglobin [11], but in this study this association was not apparent. Similarly there was no association between aggregation and the arachidonic acid level or with any of the platelet phospholipid fatty acids which take part in prostaglandin biosynthesis. The changes in these fatty acids are therefore likely to be secondary. In the Type 1 diabetic patients the changes in linoleic acid and arachidonic acid levels are consistent with impairment of the desaturase pathway which normally converts linoleic to arachidonic acid [25]. Increased thromboxane synthesis would also contribute to a lowering of arachidonic acid levels.

In other studies [26] we have observed an influence of the $\omega 3$ fatty acids on ADP-induced aggregation in Type 2 diabetic patients during a period of improving diabetic control. This paper suggests that this may not be the principal influence. Many factors are likely to affect the degree of aggregation in diabetic patients. The results of this study suggest that blood glucose level is the primary determinant. 


\section{References}

1. Szirtes M (1970) Platelet aggregation in diabetes mellitus. Adv Cardiol 4: 179-186

2. Sagel J, Colwell JA, Crook L, Laimins M (1975) Increased platelet aggregation in early diabetes mellitus. Ann Intern Med 82: 733-738

3. Juhan I, Buonocore M, Jove R, Vague PH, Moulin JP, Vialettes B (1982) Abnormalities of erythrocyte deformability and platelet aggregation in insulin dependent diabetics corrected by insulin in vivo and in vitro. Lancet 1: 535-539

4. Marcus AJ (1978) The role of lipids in platelet function with particular reference to the arachidonic acid pathway. $J$ Lipid Res 19: 793-820

5. Evans RJ, Lane J, Holman RR, Turner RC (1982) Induced basal normoglycaemia and altered platelet aggregation in non-insulin dependent diabetes. Diabetes Care 5: 433-437

6. Giugliano D, Misso L, Tirelli A, Coppola L, Di Pinto P, Torella R (1982) Platelet aggregation after strict metabolic control using the artificial pancreas. Diabetologia 23: p 545

7. Eldor A, Merin S, Baron H (1978) The effect of streptozotocin diabetes on platelet function in rats. Thromb Res 13: 703-714

8. Moncada S, Vane JR (1977) Arachidonic acid metabolites and the interactions between platelets and blood vessel walls. $\mathrm{N}$ Engl $\mathrm{J}$ Med 300: 1142-1147

9. Halushka RV, Rogers RC, Loadholt CB, Colwell JA (1981) Increased platelet thromboxane synthesis in diabetes mellitus. J Lab Clin Med 97: 87-96

10. Ylikorkala O, Kaila I, Viinikka J (1981) Prostacyclin and thromboxane in diabetes. Br Med J 283: 1148-1150

11. Jones DB, Carter RD, Haitas B, Mann JI (1983) Low arachidonic acid values in diabetic platelets. Br Med J 286: 173-175

12. Dyerberg J, Bang HO, Aagaard O (1980) Alpha linolenic acid and eicosapentaenoic acid. Lancet 1: 199

13. Raz A, Minkes MS, Needleman P (1977) Endoperoxides and thromboxanes - structural determinants for platelet aggregation and vasoconstriction. Biochem Biophys Acta 488: 305-311

14. Jones DB, Haitas B, Carter RD, Bown E, Mann JI (1984) Prostaglandin synthesis inhibition reduces platelet aggregation in diabetes mellitus. Horm Met Res 17: 42-43

15. Hampton JR (1985) Platelets and coronary disease: round three. Br Med J 290: 414-415

16. Jeppson JO, Franze B, Gaal AB (1980) Simplified determination of haemoglobin A1c in diabetic patients by use of isoelectric fo- cussing. In: Radola BS (ed) Electrophoresis 1979. Advanced methods: biochemical and clinical applications. Walter de Gruyter, Berlin

17. Albano JDM, Ekins RP, Maritz G, Turner RC (1972) A sensitive precise radioimmunoassay of serum insulin relying on charcoal separation of bound and free moieties. Acta Endocrinol 70: 487-509

18. Ononogba IC, Lewis B (1976) Lipoprotein fraction by a precipitation method: a simple quantitative procedure. Clin Chem Acta 71: 397-402

19. Burstein M, Scholnick HR, Morfin R (1970) Rapid method for the isolation of lipoproteins from human serum. Precipitation with polyanions. J Lipid Res 11: 583-595

20. Wahlefeld AW (1974) Triglycerides: determination after enzymatic hydrolysis. In: Bergmeyer HU (ed) Methods of enzymatic analysis. Academic Press, New York London, p 1836

21. Lawrence RD (1963) Treatment of 90 severe diabetics with soluble insulin for 20-40 years. Effect of diabetic control on complications. Br Med J 2: 1624-1626

22. Dornan TL, Mann JI, Turner RC (1982) Factors protective against retinopathy in insulin dependent diabetics free of retinopathy for 30 years. Br Med J 285: 1073-1077

23. Karpatkin S (1967) Studies on human platelet glycolysis. Effect of glucose, cyanide, insulin, citrate and agglutination and contraction on platelet glycolysis. J Clin Invest 46: 409-414

24. Karpatkin S, Charmatz A, Langer RM (1970) Glycogenesis and glyconeogenesis in human platelets. Incorporation of glucose, pyruvate, and citrate into platelet glycogen: glycogen synthetase and fructose 1-6 diphosphatase activity. J Clin Invest 49: 140-149

25. Brenner RR (1971) The desaturation step in the animal biosynthesis of polyunsaturated fatty acids. Lipids $6: 567-575$

26. Jones DB, Haitas B, Bown EG, Carter RD, Barker K, Jelfs R, Turner RC, Mann JI, Prescott RJ (1986) Platelet aggregation in non-insulin dependent diabetes is associated with platelet fatty acids. Diabetic Med 3: $52-55$

Received: 12 August 1985

and in revised form: 3 February 1986

Dr. D. B.Jones

Department of Medicine

Western General Hospital

Edinburgh EH4 2XU

UK 